\title{
Normas para la presentación de trabajos
}

\author{
La Revista de la Escuela de Salud Pública de la \\ Facultad de Ciencias Médicas de la Universidad Nacional \\ de Córdoba, destinada a la publicación de la Producción \\ técnico-científica relacionada al área de la salud y en \\ especial de la Salud Pública. Publicación semestral.
}

\section{Normas Editoriales}

- Estas normas están basadas en la traducción del documento "Requisitos uniformes para manuscritos presentados a revistas biomédicas" (estilo Vancouver) del Comité Internacional de Editores de Revistas

- Serán aceptados en cada número, un máximo de dos manuscritos originales por autor, destinados exclusivamente a la revista de la Escuela de Salud Pública. Serán evaluados por pares (2) que son parte de los consultores constantes en la composición del Comité de Redacción.

- Los manuscritos deberán ser enviados acompañados de una carta de solicitud de publicación, indicando dirección, teléfono/fax y e-mail para contacto con el/la (os/as) autor/a (es) (as) responsable (es), especifique la clasificación del tipo de artículo, y complete la declaración de esclusividad de destino del artículo a la revista de la Escuela de Salud Pública.

- Serán aceptados manuscritos en portugués, inglés y español

- El Comité de Redacción asegura el anonimato de el los(as) autores (as)en el proceso de evaluación por los dos consejeros designados, del Consejo Científico, como también es asegurada la reserva de identidad de los evaluadores que participan, permitiendo libertad en su evaluación

- El Comité de Redacción se reserva el derecho de no aceptar los manuscritos o de sugerir evaluantes, modificaciones de estructura o contenido, que serán comunicados a el/ los (as) autores (as). No serán admitidos agregados o alteraciones del texto, después del envío para su edición.

- Los autores de los manuscritos no aceptados para publicación serán notificados, para lo cual la justificativa de la no aceptación, será alcanzada a aquellos autores que la soliciten

- Los manuscritos resultantes de la investigación, o relato de experiencia vinculada a seres humanos, deberán indicar si los procedimientos desarrollados respetan las pautas establecidas en la Declaración de Helsinki (1975 y revisada en 1983)

- Manuscritos presentados en eventos (congresos, simposios, seminarios, entre otros) serán aceptados mientras que no hayan sido publicados integramente en anales y que tengan autorización, por escrito, de la entidad organizadora del evento, cuando las normas del evento 
asi lo exigieran. Excepcionalmente serán aceptados manuscritos ya publicados en periódicos extranjeros, mientras que sean autorizados por el Comité Editorial del periódico, en que el manuscrito haya sido originalmente publicado.

- Opiniones y conceptos emitidos en los artículos, así como la exactitud, adecuación y procedencia de las situaciones bibliográficas, son de exclusiva responsabilidad de el los/ as autores (as), no influyendo necesariamente la posición del Consejo de Redacción.

- El/los (as) autores (as) deberán presentar una declaración de responsabilidad y transferencia de derechos de autoría, en ocasión de envío del texto final del artículo después de atendidas las reformulaciones solicitadas por el Consejo de Redacción.

- Los artículos publicados serán de propiedad de la Revista, impidiendo cualquier reproducción total o parcial en cualquier otro medio de divulgación, impresa o electrónica, sin la previa autorización de la Revista.

\section{Categorías De Los Artículos}

La Revista clasificará los artículos de acuerdo con las siguientes secciones: editorial, artículo original, resumenes de tesis y disertaciones, comunicación breve, revisión de literatura, entrevista, foro de opinión, reseña.

EDITORIAL: materia de responsabilidad del Comité de Redacción de la revista. El Comité podrá invitar autoridades para escribirlo. Límite de dos páginas.

ARTÍCULOS ORIGINALES: límite de 15 páginas. Son considerados dentro de esta sección:

Investigación: relato de resultados de investigación concluida

Relato de experiencia: descripciones de experiencia académica, asistencial y de extensión

Reflexión: presenta material de carácter opinativo y/o análisis de cuestiones que puedan contribuir para profundizar los temas relacionados al área de salud y de la Salud Pública a la que se destina la revista

El manuscrito debe presentárselo considerando los siguientes requisitos:

- Título del artículo en inglés y español

- Nombre completo de el / los (as) autores (as) digitado en espacio simple en el margen derecho de la página, indicando en nota a pie de página los títulos académicos, cargos ocupados y nombre de la institución a la cual el / los (as) autores (as) están vinculados.

- Resumen: en españoles e inglés, destacando objetivos, método, resultados y conclusiones, con límite de 150 palabras

- Descriptores, palabras clave identificando el contenido del artículo. Constituido de 3 a 5 "palabras clave" en los dos idiomas. Para determinarlos debe consultar la lista de Descriptores en Ciencias de la Salud (DECS), elaborada por la bireme y disponible en la internet en el site: http://www.bireme.br.

- Texto: ordenado en introducción, desarrollo y conclusión

- Ilustraciones: (fotos, tablas, gráficos, figuras, cuadros) deben ser enumeradas consecutivamente en números arábigos, con sus respectivas leyendas y fuentes. Enumerar consecutivamente por el orden de citación en el texto:

- Las citaciones directas, seran presentadas en el texto entre comillas, indicando el número de la referencia y la página de la citación

- Notas de pie de página: serán indicados por asteriscos y restrictas al mínimo.

- Referencias bibliográficas: conforme estilo "Vancouver".

- Anexos: después de las referencias bibliográficas.

- Dirección completa, teléfono/ fax y e-mail del primer autor del texto.

RESUMEN DE TESIS Y DISERTACIONES: espacio destinado a la divulgación de tesis y disertaciones concluidas.

Debe contener:

- Título en inglés, portugués y español

- Nombre completo del (la) autor (a) (digitado en espacio simple, en el margen derecho de la página) indicando en nota pie de página el título académico, cargo ocupado y nombre de la institución a la cual esta vinculado y el Programa de Postgrado donde concluyó el 
maestrado o doctorado

- Referencia bibliográfica de la tesis o disertación de acuerdo con el estilo "Vancouver"

- Nombre del (la) orientador (a)

- Resumen informativo con hasta 500 palabras, en portugués, en español e inglés (iniciando por el idioma original de la tésis o disertación)

- Dirección completa, teléfono/ fax y e-mail del (la) autor (a).

COMUNICACiÓN BREVE: espacio destinado a la divulgación de investigaciones, de experiencias, y de tesis o disertaciones en desarrollo, debiendo contener:

- Tipo de estudio, objetivos, metodología y práctica clínica de desarrollo

- Límite de 2 páginas, observando la secuencia

- Titulo en portugués, inglés y español

- Nombre completo del (la) autor (a) (digitado en espacio simple, en el margen derecho de la página) indicando en nota pie de página el título académico, cargo ocupado y nombre de la institución a la cual el/la (os/as) autor/a (es/as) esta (n) vinculado/a (os)(as)

- Nombre del (la) orientador (a) cuando se trate de proyecto de tesis o disertación

-Referencia bibliográfica cuando hubiera, de acuerdo con el estilo"Vancouver"

- Dirección completa, teléfono/ fax y e-mail del (la) primer(a) autor (a).

REVISIÓN DE LA LITERATURA: refiere evaluación de literatura sobre temas específicos. Debe incluir el procedimiento adoptado, su delimitación y conclusiones. Límite de 10 páginas. Las demás orientaciones, seguir las normas de los artículos originales

ENTREVISTA: espacio destinado a entrevistas de autoridades / especialistas/ investigadores. Límite de 5 páginas.

FORO DE OPINIÓN: Espacio destinado a la divulgación de opiniones, lanzamientos o indicaciones de publicaciones, realizaciones de eventos y prácticas del área académica y asistencial. Límite de 3 páginas.

RESEÑA: espacio destinado a la síntesis o análisis interpretativa de las obras recientemente publicadas. Límite de 4 páginas y observar la secuencia:

- Titulo en inglés y español

- Nombre completo del (la) autor (a) (digitado en espacio simple, en el margen derecho de la página) indicando en nota pie de página el título académico, cargo ocupado y nombre de la institución a la cual el/la (os/as) autor/a (es/as) esta (n) vinculado/a (os)(as)

- Referencia bibliográfica de la obra analizada conforme al estilo "Vancouver"

- Dirección completa, teléfono/ fax y e-mail del (la) primer(a) autor (a).

\section{Modelo De Representación}

Los manuscritos deben ser redactados en la ortografía oficial y digitado con espacio de $1,5 \mathrm{~cm}$. en el margen izquierdo y superior sera de $3 \mathrm{~cm}$ y en el margen derecho e inferior de $2 \mathrm{~cm}$. Letra Times New Roman 12 o superior, utilizando editor Word for Windows 98 o Editores que sean compatibles. El envío del manuscrito debe ser en tres ejemplares impresos (1 original y 2 copias), juntamente con el disquete gravado. El texto debe estar organizado sin numeración progresiva para título y subtítulo, debiendo ser diferenciado a través del tamaño de la fuente utilizada.

\section{Ejemplo De Referencia Bibliográfica:}

Las referencias bibliográficas deben estar enumeradas consecutivamente, en el orden que aparecen en el texto por primera vez, y estar de acuerdo con el estilo "Vancouver" (J Pediatr 1997; 73:213-24, actualización de octubre del 2001). 